\title{
BMJ Global Health Rethinking the cost of healthcare in low-resource settings: the value of time-driven activity-based costing
}

\author{
Ryan K McBain, ${ }^{1}$ Gregory Jerome, ${ }^{2}$ Jonathan Warsh, ${ }^{3}$ Micaela Browning, ${ }^{1}$ \\ Bipin Mistry, ${ }^{3}$ Peterson Abnis I Faure, ${ }^{2}$ Claire Pierre, ${ }^{2,4}$ Anna P Fang, ${ }^{5}$ \\ Jean Claude Mugunga, ${ }^{1}$ Joseph Rhatigan, ${ }^{4,6}$ Fernet Leandre, ${ }^{2}$ Robert Kaplan ${ }^{3}$
}

To cite: McBain RK, Jerome G, Warsh J, et al. Rethinking the cost of healthcare in low-resource settings: the value of timedriven activity-based costing. BMJ Global Health 2016;1: e000134. doi:10.1136/ bmjgh-2016-000134

Received 20 July 2016 Revised 23 September 2016 Accepted 26 September 2016

\section{(a) CrossMark}

${ }^{1}$ Partners in Health, Boston, Massachusetts, USA

${ }^{2}$ Zanmi Lasante, Port-auPrince, Haiti

${ }^{3}$ Harvard Business School, Boston, Massachusetts, USA ${ }^{4}$ Harvard Medical School, Boston, Massachusetts, USA ${ }^{5}$ Analysis Group, Inc., Boston, Massachusetts, USA ${ }^{6}$ Dept of Global Health Equity, Brigham and Women's Hospital, Boston,

Massachusetts, USA

\section{Correspondence to}

Dr Ryan K McBain; rmcbain@ pih.org and rmcbain@mail. harvard.edu

\section{ABSTRACT}

Low-income and middle-income countries account for over $80 \%$ of the world's infectious disease burden, but $<20 \%$ of global expenditures on health. In this context, judicious resource allocation can mean the difference between life and death, not just for individual patients, but entire patient populations. Understanding the cost of healthcare delivery is a prerequisite for allocating health resources, such as staff and medicines, in a way that is effective, efficient, just and fair. Nevertheless, health costs are often poorly understood, undermining effectiveness and efficiency of service delivery. We outline shortcomings, and consequences, of common approaches to estimating the cost of healthcare in lowresource settings, as well as advantages of a newly introduced approach in healthcare known as timedriven activity-based costing (TDABC). TDABC is a patient-centred approach to cost analysis, meaning that it begins by studying the flow of individual patients through the health system, and measuring the human, equipment and facility resources used to treat the patients. The benefits of this approach are numerous: fewer assumptions need to be made, heterogeneity in expenditures can be studied, service delivery can be modelled and streamlined and stronger linkages can be established between resource allocation and health outcomes. TDABC has demonstrated significant benefits for improving health service delivery in highincome countries but has yet to be adopted in resource-limited settings. We provide an illustrative case study of its application throughout a network of hospitals in Haiti, as well as a simplified framework for policymakers to apply this approach in low-resource settings around the world.

\section{INTRODUCTION}

The way resources are allocated to address health needs can have widespread impacts on the well-being of country populations. This is particularly true where resources are limited. Compared with annual healthcare expenditures in OECD countries, which average $\$ 4000$ per person, annual expenditures in low-income countries average $\$ 40$ per person-a 100 -fold difference. ${ }^{1}$

\section{Key questions}

What is already known about this subject?

- The cost of providing healthcare is often poorly understood.

- Common approaches for evaluating health costs, such as those developed by the World Health Organization and World Bank, have significant shortcomings.

\section{What are the new findings?}

- Time-driven activity based costing (TDABC) is a methodology that allows providers and staff to observe resource costs at the patient-level in order to inform delivery of care.

- This manuscript provides an overview of the comparative advantages of TDABC, as well as a set of resources for conducting TDABC in lowresource settings.

What are the recommendations for policy and practice?

- We recommend that policymakers, hospital staff and health systems specialists apply the principles of TDABC in order to improve both health cost estimates and resource allocation for health service delivery.

Meanwhile, the burden of infectious disease is roughly 40 times greater on a per capita basis. $^{2}$ As such, the centrality of constrained costs in low-resource settings is absolute and unavoidable (see figure 1).

Phrases like 'value for money', 'costeffectiveness' and 'return on investment' are ubiquitous. There is, however, a disconnect between this rhetoric and the availability of decision-making tools for healthcare providers and payers. ${ }^{34}$ Reasons for this are varied: political constraints within and beyond the health sector, ${ }^{5}{ }^{6}$ logistical challenges with data collection $^{78}$ and ethical considerations. ${ }^{9} 10$ Underpinning each is a weak understanding of the means by which we measure costs and value in healthcare provision. ${ }^{11}$ 


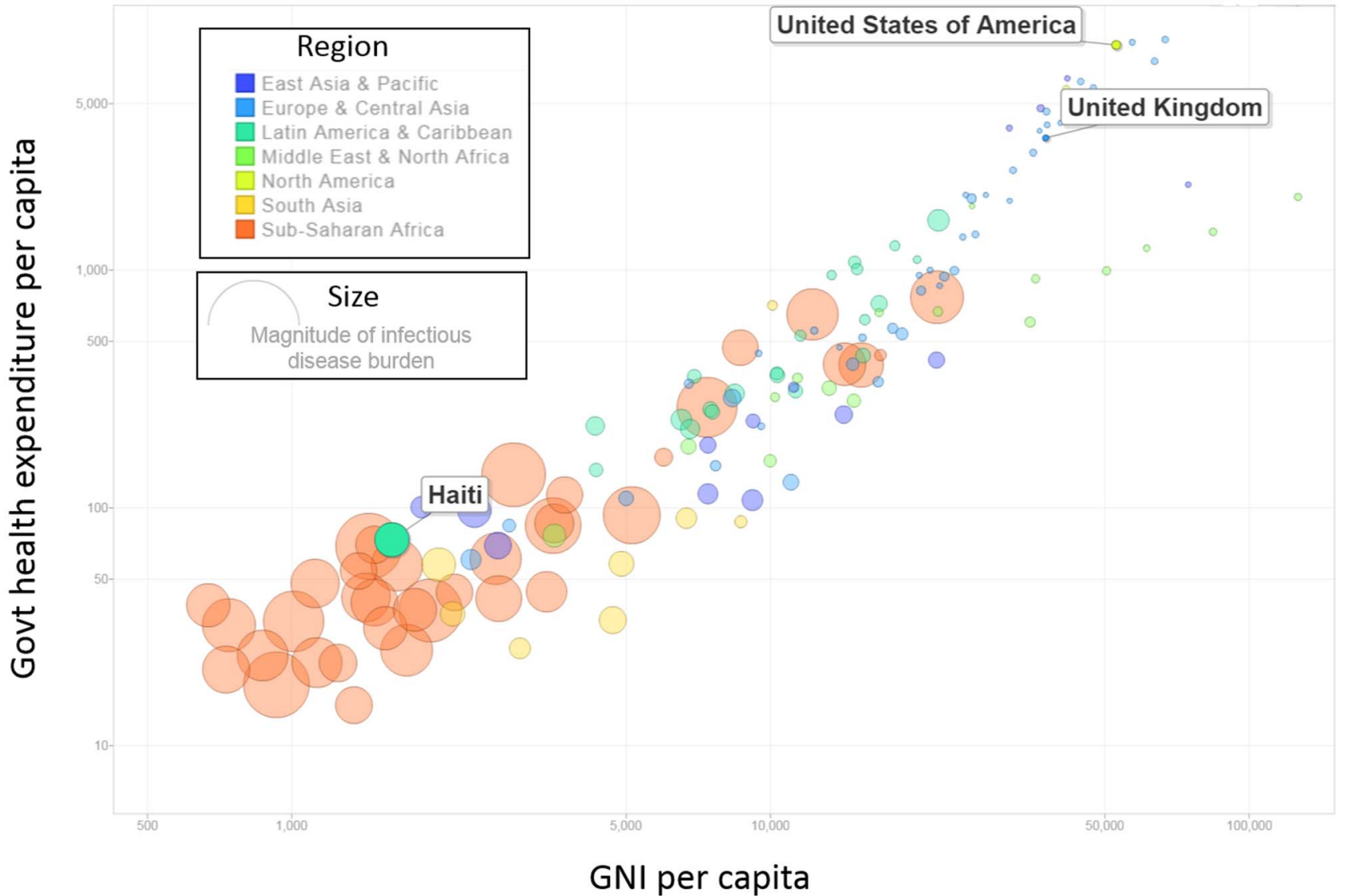

Figure 1 Country wealth, government health expenditures and infectious disease in 150 countries. The size of each bubble represents the magnitude of the infectious disease burden in countries around the world, in disability-adjusted life years per capita. While high-income countries like the USA and UK spend over US $\$ 3500$ per capita per year on healthcare, the magnitude of infectious disease is minuscule. Comparatively, low-income countries like Haiti spend <US $\$ 100$ per capita per year on healthcare and have a much larger burden of infectious disease. Note that the log-distributions of GNI per capita and government health expenditures per capita are presented above.

\section{UNDERSTANDING HEALTHCARE COSTS}

Even in high-income countries like the USA and UK, costs are rarely examined at the level of the patient and their medical condition. Rather, they are viewed through the prism of charges for services rendered (ratio of cost-to-charges approach), ${ }^{12}$ or approximations of the skill level needed to perform the service (relative value unit (RVU) approach). ${ }^{13} 14$ In the former, hospitals aggregate costs at the service department level, and arbitrarily assume a direct relationship between costs for a service and what the hospital charged the payer. ${ }^{15}$ In the latter, hospitals use RVU-based formularies that assign cost based on the level of training needed to perform a given service. ${ }^{16}$ In neither case are costs understood as the actual consumption of resources-the time of clinical staff and equipment, the spending on materials and utilities-used to achieve patient outcomes.

The ramifications of this omission are profound, particularly in poorer countries where resources are scarce. At face value, ignoring the actual cost of patient care impedes the ability to improve efficiency, reduce the cost of care and associate costs with patient outcomes. ${ }^{17}$ While a certain amount of inefficiency is inevitable in any system, the consequences are much more severe in low-resource settings. Additionally, equating cost with reimbursement for services leads to further distortion by incentivising providers to increase the quantities of highly reimbursed services, regardless of value to patients, and discouraging the use of poorly reimbursed but high-value interventions, such as counselling patients and their families. ${ }^{18}$ This can inflate long-term costs for patients because they are not provided with optimal care.

\section{THE EXISTING LANDSCAPE}

From an implementation perspective, many low-resource settings cannot apply methods utilised in settings like the USA or UK: facilities in these settings rarely have charge data available, and their medical billing information lacks the level of specificity necessary to leverage an RVU-type model. Recognising these constraints, policymakers, economists and researchers in low-income and middle-income countries have developed several frameworks for measuring costs. Two of the most frequently referenced are the WHO-CHOICE framework of the 
WHO, and a suite of manuals, tools and reports developed by the World Bank.

The WHO-CHOICE framework uses a bottom-up approach to cost aggregation, with an emphasis on studying sector-wide strategic health plans and policies. ${ }^{19}$ In practice, 'bottom'-up approaches assign individual expenditures to cost centres-such as infrastructure and human resources-and estimate the extent to which cost centres serve the programme, plan or policy in question. ${ }^{20}$ While the considerations accounted for by WHO-CHOICE are specific, ${ }^{21}$ neither the WHO-CHOICE framework nor the associated OneHealth Tool is designed to monitor time and resource utilisation at the level of the individual patient's health conditions. ${ }^{22}$ The same can be said for other cost-effectiveness analysis manuals developed by the WHO that extend beyond the scope of WHO-CHOICE. ${ }^{23} 24$

A second series of costing tools, developed by the World Bank, outlines a broader array of approaches. These include bottom-up methods akin to the WHO-CHOICE model, and top-down approaches in which total expenditures for an intervention or service - defined, for example, by level of funding availableare divided by total service units. ${ }^{25}{ }^{26}$ In all cases, the strength of these approaches lies in their ability to quickly produce estimates for macro-level priority setting. However, from a management perspective, examination of department and service level costsrather than per-patient estimates-preclude individuals from looking at heterogeneity in the cost of care delivery across patients, hospitals and physicians. Additionally, they often fail to measure costs over the life cycle of a patient's medical condition, impeding the development of value-based reimbursement models: These models inherently depend on the ability to reimburse based on the value produced to the patient, and requires observation of patient outcomes over a longer time horizon than that typically selected as the unit of analysis-such as a single patient visit.

\section{TIME-DRIVEN ACTIVITY-BASED COSTING}

In contrast to these approaches, a newer costing method, known as time-driven activity-based costing (TDABC), has been at the forefront of reforms in highincome countries and has yielded significant cost savings at healthcare facilities throughout the USA and Europe. ${ }^{27}$ Compared with the approaches outlined above, the principle underpinning TDABC is different: measure the costs of all the resources used to treat a patient's medical condition over a complete cycle of care. In this way, costs and outcomes can be measured accurately at the patient level. While also a 'bottom-up' approach to costing, TDABC focuses on the costs incurred at the patient level, which facilitates discussions about care delivery innovation and reforms to payment systems.

In practice, implementing the TDABC approach follows a four-step procedure: inductively determine the care processes for individual patients by shadowing them; calculate cost rates for personnel and equipment; measure spending on consumables; and allocate indirect costs in a causal manner. Colloquially, the content can be thought of in terms of: activities, people, materials and remainders. We review each, briefly, in conjunction with the antenatal care (ANC) process map outlined in figure 2.

- Activities. What activities are performed over the cycle of care for a condition, who performs each activity and how long do they spend on each activity? In the example of an ANC visit, as outlined in figure 2, seven activities are performed. The second of these, registration, is performed by an archivist, who takes 9 min to perform the task.

- People. What is the cost, per unit of time, for each type of personnel and equipment used during the care cycle? The answer to this question generates capacity cost rates. For instance, an archivist in Haiti works 6 hours a day, 5 days a week, for 50 weeks a year -at a salary of US $\$ 2000$ /year. Seen this way, an archivist's capacity cost rate is US $\$ 0.022 / \mathrm{min}$ : US $\$ 2000$ divided by $90000 \mathrm{~min}$.

- Materials. What materials, supplies and drugs are consumed during the care cycle? For example, during physician consultation, consumables might include testing strips and latex gloves.

- Remainders. What are the additional costs incurred that are not directly consumed over the cycle of care? Indirect costs are those that do not directly contribute to individual patient care, but are nevertheless expended. For instance, this would include costs such as salary of administrators, health systems information technology and janitorial support.

The TDABC approach has several clear benefits relative to traditional costing approaches. First, compared with top-down estimates, providers can ascertain the cost of care for specific treatment pathways-for example, they can compare the cost of a normal vaginal delivery with a caesarean section. ${ }^{28}$ Second, compared with other bottom-up methods of costing, TDABC data are collected at the patient-level, rather than the service or cost centre level. This allows for the measurement of additional costs incurred to treat persons with high risk factors for that medical condition, such as age, obesity, substance abuse and comorbidities. Third, by associating time contributed by resources to specific conditions, providers learn how much of their resources' capacity are allocated to certain activities relative to others. ${ }^{29}$

Fourth, directly tracing the patient flow through a facility is a way of inductively modelling the existing system of care for a given condition, thereby generating discussion about the ways in which this system may be optimised over the care cycle to create better outcomes and efficiencies. ${ }^{30}$ For example, there may be activities where a lower-paid person could be substituted, without compromising patient care and quality, for an expensive physician or nurse, which enables scarce personnel 
STEP 1

STEP 2

STEP 3

STEP 4
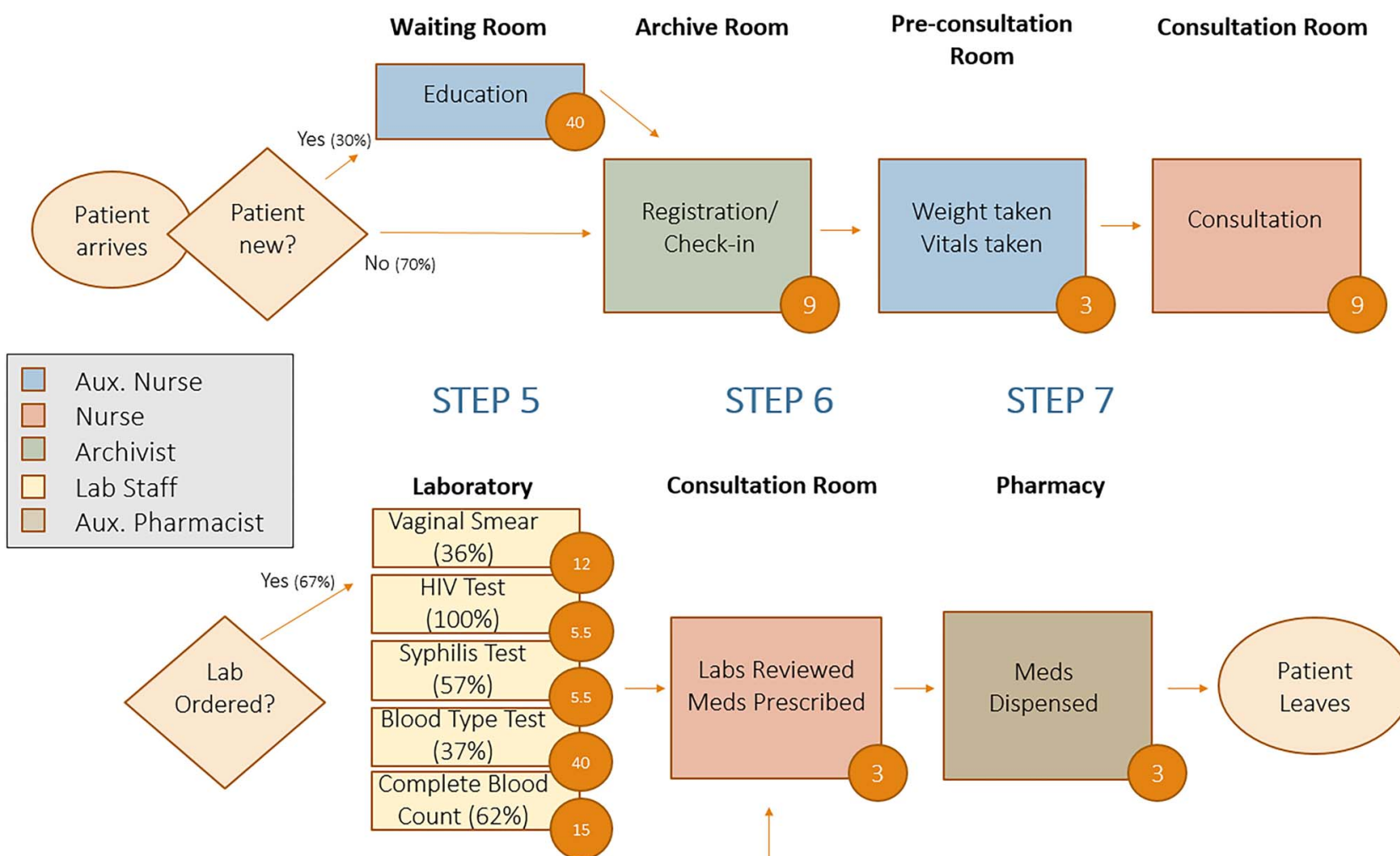

Consultation Room

STEP 7

\section{STEP 5}

STEP 6

Pharmacy

No $(33 \%)$

Figure 2 Process map of antenatal care visit in Haiti. Time stamps for each step of patient care are presented in each of the orange circles. Rectangles represent activities in the cycle of care, while diamonds represent decision nodes.

1. Interview Guide for process mapping

- $\quad$ https://drive.google.com/a/mail.harvard.edu/file/d/OB_vpAM_tV_pjQWNIcUR5VTM4ZEE/view?pref=2\&pli=1

2. Instruction Manual for producing TDABC cost estimates_antenatal care illustrative example

Figure 3 Resources for conducting time-driven activity-based costing.

resources to be freed up for clinical activities that only they can perform. Last, and perhaps most critically, to the extent that patient outcomes are associated with the patient costs produced by TDABC, one can begin to draw linkages between resource utilisation and improvements in patient health. ${ }^{31}$

\section{OBSTACLES TO IMPLEMENTATION}

TDABC has been applied almost exclusively in highincome countries, although there are a few notable exceptions ${ }^{32}{ }^{33}$ in which staff time has been directly estimated. The limited adoption of TDABC in resourceconstrained settings can be explained by the lack of a standard set of tools or curricula to apply this approach. Additionally, the approach requires greater technical expertise and resources than the other approaches. Finally, most data necessary to produce estimates are either non-existent, difficult and time-consuming to obtain, or of poor quality in such settings.

None of these obstacles is insurmountable. In figure 3, we provide two tools for implementing TDABC in resource-constrained settings. The tools correspond to a simplified approach, using lay people to document patient flow and catalogue resources expended. We believe that following this framework should generate information of the quality necessary to harness the benefits of this costing approach. To support this, we have outlined a short case study from implementation in Haiti, which highlights the ways in which application of TDABC can be used to inform decision-making by policymakers and hospital administrators.

\section{A CASE STUDY: HAITI}

Haiti is the poorest country in the western hemisphere. The average income per capita is US\$800/year. ${ }^{34}$ In 
terms of health, the average life expectancy is 63 years; ${ }^{35}$ 1 in 15 children do not live to see their fifth birthday, ${ }^{36}$ and 1 in 90 women die from causes related to pregnancy and childbirth. ${ }^{37}$ Partners in Health (PIH) has been working in Haiti for over 25 years. Utilising the resources outlined in figure 3, over the past year, PIH implemented TDABC at five health centres, representing a cross section of our primary and secondary health centres (figure 4). Ethics approval for this study was provided by the Zanmi Lasante Institutional Review Board. Understanding costs at the patient-level enabled staff to gain insights on process improvements, predictive analytics and health financing strategies.

The mapping of the flow of clinical services was used to identify and reduce variation in the care provided for particular conditions across the network. It also allowed the organisation to pinpoint shortcomings in resources; for example, the underprescription of medicines due to stock-outs. Third, TDABC directly observes staff time allocations to specific activities, including instances in which specialised staff perform activities that could be performed by more general staff. This, in turn, catalysed discussions about the distribution of healthcare throughout a network-for instance, task-shifting some level of service delivery to community health workers in order to increase patient access to care.

Predictive analytics have allowed us to use the data to forecast costs. For example, we were able to examine current and expected volume of ANG visits over the next year-based on demographic trends in population growth and fertility rates-allowed us to project expected cost over the next year. Data at the patient-level also enabled us to examine heterogeneity in costs-within and between facilities. Figure 5 provides an illustration of this. The average initial ANC visit at Hospital St Nicholas (HSN, $\mathrm{n}=355$ ), a district-level hospital in $\mathrm{St}$ Marc, cost $\$ 24.95$ ( $\mathrm{SD}=\$ 2.75)$. Comparatively, the cost at Lacolline Health Center $(n=282)$, a lower-level facility in Lascahobas, cost $\$ 11.02(\mathrm{SD}=\$ 3.67)$. This difference was highly statistically significant $(\mathrm{p}<0.001)$ and reflected the fact that HSN had more specialised and higher-paid staff providing routine ANC.

Heterogeneity within and between facilities also reflected sources of variation such as stock-outs in medicines at specific facilities, which allowed us to reassess our supply chain. Underutilisation of medicines due to stock-outs was identified in two ways: first, when physicians failed to prescribe medicines that were obvious for certain conditions-such as antihypertensives for patients with hypertension-physicians were interviewed and stated the reason as stock-outs. Second, distribution of medicines to patients, and the absence of this activity due to stock-outs, was documented in real time by staff who shadowed pharmacists.

Finally, an accurate understanding of costs allowed for a valuation of the care we provide, including an entry

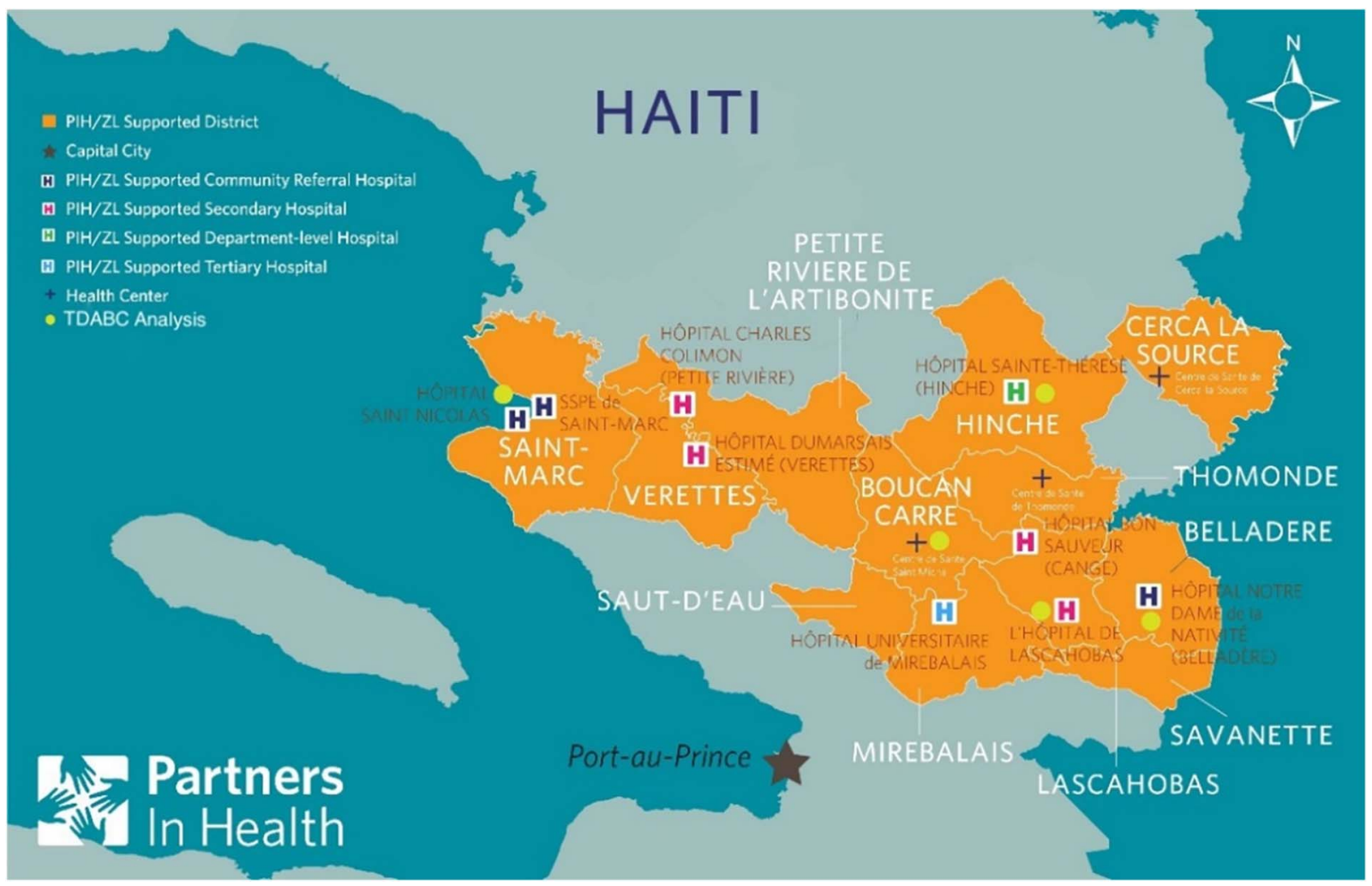

Figure 4 Map of Haiti where time-driven activity-based costing (TDABC) data were collected. Orange area represents the catchment region of Zanmi Lasante. ' $H$ ' marks a Zanmi Lasante health facility, and those with a yellow dot represent facilities incorporated in the TDABC analysis. 


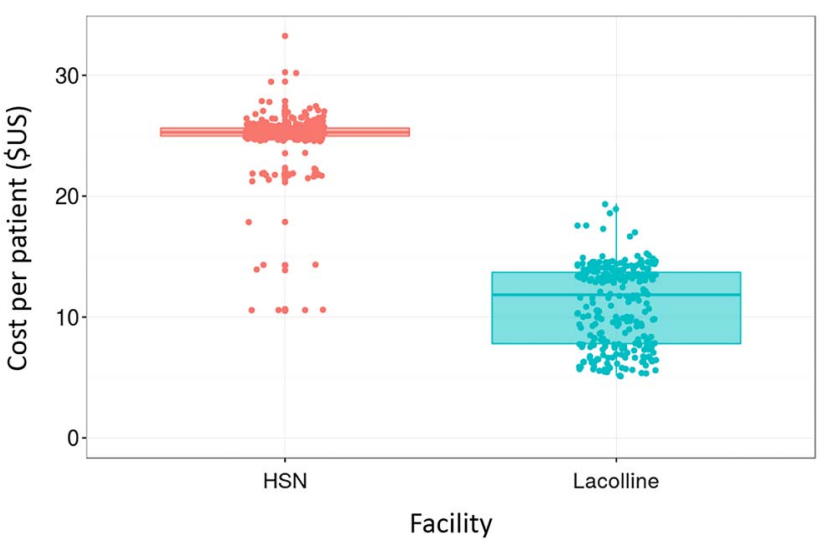

Figure 5 Variation in cost of an antenatal care visit, by patient and facility. Information collected at Zanmi Lasante hospitals in Lascahobas and St Marc, Haiti, based on direct observation of patients and interviews with providers. Each dot represents the cost of a patient to the system, in USD. Observations two or more SDs above and below the mean were excluded from the figure.

point for negotiating the price of health services. PIH provides healthcare for those who would not typically be able to afford unsubsidised care. Knowing the cost of our care therefore allowed the organisation to justify-to both private funders and private and public insurersthe value placed on services, and advocate for further investments.

Much of the improvements described above would not have been possible with other costing approaches. To provide an illustrative example, we analysed service-level cost data from Lacolline using the WHO-CHOICE framework. The resulting ANC visit cost estimate produced by this differed modestly from that produced by TDABC. However, the WHO-CHOICE method required significantly more assumptions about percentage of staff time allocated to activities with patients, which were directly observed and documented using TDABC. Additionally, the direct observation inherent in TDABC gave transparency into the care process and allowed for the creation of a CI around our point estimate, as well as exploration of heterogeneity in costs across patientsby provider, by patient type, by service and facility. As noted above, exploration of this heterogeneity presented opportunities to reduce patient-level variance in costs by streamlining protocols and processes, and allowed us to identify variance accounted for by medicine stock-outs and broken laboratory equipment.

\section{LIMITATIONS OF TDABC}

There are several limitations to TDABC. First, conducting TDABC is time-intensive, requiring 2-3 personnel to commit roughly 20 hours per condition examined. In low-resource settings like Haiti, this may translate to several hundred or thousand dollars' worth of staff time. Institutions looking at pursuing this approach would do well to focus first on high-volume and high-cost conditions.

Second, conclusions reached from TDABC may not always translate in the real world. For example, 'pushing' care down to a lower level of the tertiary care system may not work in a setting with significant geographic and transportation barriers.

Third, apart from the complementary assessment of patient outcomes, TDABC should be seen as a descriptive, rather than prescriptive, tool. In low-income and middle-income countries, it is likely that the cost of care is below that which would be adequate to achieve ideal patient outcomes. For example, observing that a physician spends only $3 \mathrm{~min}$ in consultation with a patient is not a sign of the physician's efficiency or productivity. More likely, it indicates inadequate staffing levels and overall resource scarcity, producing cost estimates far below those necessary to deliver adequate care. In other words, TDABC can help us understand the cost of care delivery as it stands today, but it does not tell us what the cost of care would be in an optimised world.

Fourth, TDABC should (ideally) be compared with a top-down approach to cost analysis in which total expenditures are calculated using total units of activities: because TDABC assumes a bottom-up approach, it risks the possibility of failing to capture broader, indirect costs. This is a particularly significant barrier in lowresources settings, where indirect costs are higher due to geographic and other logistical barriers in transporting medicines, equipment, fuel and supplies to and from facilities.

Finally, in settings like Haiti, the resources utilised over a cycle of care may come from numerous organisations: for example, human resources from PIH and the Ministry of Health, and medicines from international organisations like the Global Fund. With the contribution of each additional actor, identifying and parsing out individual costs becomes increasingly challenging.

\section{CONCLUSIONS}

Traditional costing approaches in low-resource settings have been able to do little more than provide an average cost per patient. However, as health systems expand, understanding the cost of care for the individual patient's medical condition is essential for process improvement, standardisation, efficient care delivery and value-based payment systems. As governments and providers consider cost controls, fine-tuning the system to reduce inefficiencies and unwanted variation may prove more responsive than wide-scale reductions in staffing and medicine. Moreover, as low-income and middle-income countries strive towards universal health coverage, the ability to synthesise demographic and burden of disease information with robust cost analytics will enable financial planning and financing that is empirically justified. 
Handling editor Seye Abimbola

Twitter Follow Jean Claude Mugunga at @jcmugunga

Contributors RKM and JW were responsible authorship of the first draft of this manuscript, with substantive revisions and edits from GJ, MB, BM, PAIF, $\mathrm{CP}, \mathrm{APF}, \mathrm{JCM}, \mathrm{JR}$, FL and RK. PAIF, GJ, and FL led data collection in Haiti, with technical support from MB, RKM, BM and JW. Review and analysis of the data were provided by MB, RKM and PF. Methodological guidance and oversight were provided by RK, JW and BM.

Funding This study was funded by the Bill and Melinda Gates Foundation (OPP1120523).

\section{Competing interests None declared.}

Ethics approval The research protocol was approved by the Zanmi Lasante IRB.

Provenance and peer review Not commissioned; externally peer reviewed.

Data sharing statement No additional data are available.

Open Access This is an Open Access article distributed in accordance with the Creative Commons Attribution Non Commercial (CC BY-NC 4.0) license, which permits others to distribute, remix, adapt, build upon this work noncommercially, and license their derivative works on different terms, provided the original work is properly cited and the use is non-commercial. See: http:// creativecommons.org/licenses/by-nc/4.0/

\section{REFERENCES}

1. World Bank. Health expenditure per capita (current US\$) [Internet]. (Cited 2 March 2016). http://data.worldbank.org/indicator/SH.XPD. PCAP

2. WHO. Country-specific DALY estimates [Internet]. 2012 (cited 3 March 2016). http://www.who.int/healthinfo/global_burden_disease/ estimates/en/

3. Collier P, Dollar D. Aid allocation and poverty reduction. Eur Econ Rev 2002;46:1475-500.

4. Légaré $F$, Stacey $D$, Turcotte $S$, et al. Interventions for improving the adoption of shared decision making by healthcare professionals. Cochrane Database Syst Rev 2014;(9):CD006732.

5. Reich MR. The politics of reforming health policies. Promot Educ 2002;9:138-42.

6. Gupta V, Kerry VB, Goosby E, et al. Politics and universal health coverage - the post-2015 global health agenda. N Engl J Med 2015;373:1189-92

7. Haberer JE, Kiwanuka J, Nansera D, et al. Challenges in using mobile phones for collection of antiretroviral therapy adherence data in a resource-limited setting. AIDS Behav 2010;14:1294-301.

8. Chopra M, Lawn JE, Sanders D, et al. Achieving the health Millennium Development Goals for South Africa: challenges and priorities. Lancet 2009;374:1023-31.

9. Donaldson C, Currie G, Mitton C. Cost effectiveness analysis in health care: contraindications. BMJ 2002;325:891-4.

10. Arnesen T, Nord E. The value of DALY life: problems with ethics and validity of disability adjusted life years. BMJ 1999;319:1423-5.

11. Porter ME. What is value in health care? N Engl $\mathrm{J} \mathrm{Med}$ 2010;363:2477-81

12. Bai G, Anderson GF. Extreme markup: the fifty US hospitals with the highest charge-to-cost ratios. Health Aff (Millwood) 2015;34:922-8.

13. Das A, Norton EC, Miller DC, et al. Adding a spending metric to Medicare's value-based purchasing program rewarded low-quality hospitals. Health Aff (Millwood) 2016;35:898-906.
14. Kolhe NV, Eldehni MT, Selby NM, et al. The reimbursement and cost of acute kidney injury: a UK hospital perspective. Nephron Clin Pract 2014;126:51-6.

15. Agency for Healthcare Research and Quality. HCUP: cost-to-charge ratios [Internet]. 2015. https://www.hcup-us.ahrq.gov/db/state/ costtocharge.jsp

16. American Medical Association. The medicare physician payment schedule [Internet]. 2015 (cited 3 March 2016). http://www. ama-assn.org/ama/pub/physician-resources/ solutions-managing-your-practice/coding-billing-insurance/medicare/ the-medicare-physician-payment-schedule.page?

17. Kaplan RS, Porter ME. How to solve the cost crisis in health care. Harv Bus Rev 2011;89:46-52, 54, 56-61 passim.

18. Magnus SA, Smith DG. Better Medicare cost report data are needed to help hospitals benchmark costs and performance. Health Care Manage Rev 2000;25:65-76.

19. WHO. OneHealth Tool [Internet]. Geneva: WHO, 2012 (cited 3 July 2016). http://www.who.int/choice/onehealthtool/en/

20. WHO. OneHealth Tool: supporting integrated strategic health planning, costing and health impact analysis [Internet]. 2013 December; Geneva. http://www.who.int/choice/onehealthtool/ OneHealth_Tool_Supporting_integrated_strategic_health_planning pdf?ua $=1$

21. Hutton G, Baltussen R. Cost valuation in resource-poor settings. Health Policy Plan 2005;20:252-9.

22. WHO. WHO-CHOICE frequently asked questions [Internet]. Geneva: WHO, 2014 (cited 3 July 2016). http://www.who.int/choice/ cost-effectiveness/CHOICE_FAQ.pdf?ua $=1$

23. Edejer T, Baltussen R, Adam T, et al. Making choices in health: WHO guide to cost-effectiveness analysis. Geneva: WHO, 2003.

24. Shepard DS, Hodgkin D, Anthony Y. Analysis of hospital costs: a manual for managers. Geneva: WHO, 2000.

25. Langenbrunner JC, Cashin C, O'Dougherty S. Designing and implementing health care provider payment systems: how-to manuals [Internet]. Washington, DC: World Bank. https:// openknowledge.worldbank.org/bitstream/handle/10986/13806/ 48599.pdf? sequence $=1$

26. Preker A, Langenbrunner JC. Spending wisely: buying health services for the poor. Washington, DC: World Bank, 2005.

27. Kaplan RS, Witkowski M, Abbott M, et al. Using time-driven activity-based costing to identify value improvement opportunities in healthcare. J Healthc Manag 2014:59:399-412.

28. Mandigo M, O'Neill K, Mistry B, et al. A time-driven activity-based costing model to improve health-care resource use in Mirebalais, Haiti. Lancet 2015;385(Suppl 2):S22.

29. Kaplan R, Anderson SR. Time-driven activity-based costing: a simpler and more powerful path to higher profits. Harvard Business Press, 2013:283.

30. Demeere N, Stouthuysen K, Roodhooft F. Time-driven activity-based costing in an outpatient clinic environment: development, relevance and managerial impact. Health Policy 2009;92:296-304.

31. Kaplan RS. Improving value with TDABC. Healthc Financ Manage 2014:68:76-83.

32. WHO. Uganda safe motherhood programme costing study. Geneva: WHO, 1999:1-136.

33. Levin A, Dmytraczenko T, McEuen M, et al. Costs of maternal health care services in three anglophone African countries. Int $J$ Health Plann Manage 2003;18:3-22.

34. World Bank. GDP per capita, current USD [Internet]. 2015 (cited 14 June 2016). http://data.worldbank.org/indicator/NY.GDP.PCAP.PP. CD

35. World Bank. Life expectancy at birth, total (years) [Internet]. 2016 (cited 14 June 2016). http://data.worldbank.org/indicator/SP.DYN LE00.IN

36. World Bank. Mortality rate, under-5 [Internet]. 2016 (cited 14 June 2016). http://data.worldbank.org/indicator/SH.DYN.MORT

37. World Bank. Lifetime risk of maternal death [Internet]. 2016 (cited 14 June 2016). http://data.worldbank.org/indicator/SH.MMR.RISK 